\title{
Discrepancy between Health Care Rationing at the Bedside and Policy Level
}

Emil Persson, David Andersson, Lovisa Back, Thomas Davidson, Emma J ohannisson and Gustav Tinghög

The self-archived postprint version of this journal article is available at Linköping University Institutional Repository (DiVA):

http:// urn.kb.se/ resolve?urn=urn:nbn:se:liu:diva-152084

N.B.: When citing this work, cite the original publication.

Persson, E., Andersson, D., Back, L., Davidson, T., J ohannisson, E., Tinghög, G., (2018), Discrepancy between Health Care Rationing at the Bedside and Policy Level, Medical decision making, 38(7), 881887. https:// doi.org/ 10.1177/ 0272989X18793637

Original publication available at:

https:// doi.org/ 10.1177/ 0272989X18793637

Copyright: SAGE Publications (UK and US)

http:// www.uk. sagepub.com/home.nav 


\title{
Discrepancy between health care rationing at the bedside and policy level
}

\author{
Emil Persson ${ }^{\mathrm{a}}$, David Andersson ${ }^{\mathrm{b}}$, Lovisa Back ${ }^{\mathrm{c}}$, Thomas Davidson ${ }^{\mathrm{d}}$, Emma Johannisson ${ }^{\mathrm{e}}$, \\ Gustav Tinghög ${ }^{\mathrm{f}, 1}$
}

Cite this article as:

Persson, E., Andersson, D., Back, L., Davidson, T., Johannisson, E., \& Tinghög, G. (2018). Discrepancy between Health Care Rationing at the Bedside and Policy Level. Medical Decision Making, 38(7), 881-887. doi:10.1177/0272989X18793637

a PhD, Department of Management and Engineering, Division of Economics, Linköping University, SE-581 83 Linköping, Sweden. E-mail: emil.persson@liu.se

${ }^{\mathrm{b}} \mathrm{PhD}$, Department of Management and Engineering, Division of Economics, Linköping University, SE-581 83 Linköping, Sweden. E-mail: david.andersson@liu.se

${ }^{\mathrm{c}}$ MS, Department of Management and Engineering, Division of Economics, Linköping University, SE-581 83 Linköping, Sweden. E-mail: lovisa.back@nelsongarden.se

${ }^{\mathrm{d}} \mathrm{PhD}$, The National Center for Priority Setting in Health Care, Department of Medical and Health Sciences, Linköping University, SE-581 83 Linköping, Sweden. E-mail: thomas.davidson@liu.se e MS, Department of Management and Engineering, Division of Economics, Linköping University, SE-581 83 Linköping, Sweden. E-mail: emmjo805@gmail.com

${ }_{\mathrm{f}}^{\mathrm{PhD}}$, Department of Management and Engineering, Division of Economics, Linköping University, SE-581 83 Linköping, Sweden, \& The National Center for Priority Setting in Health Care, Department of Medical and Health Sciences, Linköping University, SE-581 83 Linköping, Sweden. E-mail: gustav.tinghog@liu.se

${ }^{1}$ Correspondence to: Gustav Tinghög, Department of Management and Engineering, Division of Economics, Linköping University, SE-581 83 Linköping, Sweden; Tel.: +46 733 223091; E-mail: gustav.tinghog@liu.se

Manuscript word count (body text incl. tables and figures): 3,110

Financial support for this study was provided by Ragnar Söderberg Foundation and Marianne and Marcus Wallenberg Foundation. The funding agreement ensured the authors' independence in designing the study, interpreting the data, writing, and publishing the report. 


\begin{abstract}
Background. Whether doctors at the bedside level should be engaged in health-care rationing is a controversial topic that has spurred much debate. From an empirical point of view, a key issue is whether there exists a behavioral difference between rationing at the bedside and policy level. Psychological theory suggests that we should indeed expect such a difference, but existing empirical evidence is inconclusive. Objective. To explore whether rationing decisions taken at the bedside level are different from rationing decisions taken at the policy level. Method. Behavioral experiment where participants $(n=573)$ made rationing decisions in hypothetical scenarios. Participants (medical and non-medical students) were randomly assigned to either a bedside or a policy condition. Each scenario involved one decision, concerning either a life-saving medical treatment or a quality-of-life improving treatment. All scenarios were identical across the bedside and policy condition except for the level of decision making. Results. We found a discrepancy between health-care rationing at policy and bedside level for scenarios involving life-saving decisions, where subjects rationed treatments to a greater extent at the policy level compared to bedside level (35.6\% vs. 29.3\%, $\mathrm{p}=0.001$ ). Medical students were more likely to ration care compared to non-medical students. Follow-up questions showed that bedside rationing was more emotionally burdensome than rationing at the policy level, indicating that psychological factors likely play a key role in explaining the observed behavioral differences. We found no difference in rationing between bedside and policy level for quality-of-life improving treatments $(54.6 \%$ vs, $55.7 \%$, p=0.507). Conclusions. Our results indicate a robust "bedside effect" in the lifesaving domain of health-care rationing decisions, thereby adding new insights to the understanding of the malleability of preferences related to resource allocation.
\end{abstract}

Key words: health-care rationing; individuals and groups; decision making; identifiability; experiment. 


\section{Introduction}

Rationing in the context of health care is typically defined as the withholding of potentially beneficial health care under conditions of resource scarcity [1, 2]. Medical decision makers at all levels in publicly funded health care systems are expected to ensure both equity and efficiency through fair rationing. It has been argued that rationing is especially uncomfortable for medical doctors at the bedside level since it entails a violation of the common medical norm of always doing what is best for the patient, even whilst pursuing societal interest ahead of the interest of the individual patient [3]. Whether bedside rationing should in fact be considered at all is a controversial topic that has spurred much debate [4-9]. Empirically, a key issue is whether rationing decisions taken at the bedside level will indeed be different from rationing decisions taken at other levels of the health care system. This is still an open empirical question, which we address in the current paper.

In a seminal study, Redelmeier and Tversky [10] found substantial differences between medical decisions taken on behalf of a single patient and a group of patients. In a behavioral experiment physicians and laypeople (undergraduate students) were more likely to recommend costly treatment when deciding on behalf of a single patient as opposed to a group of comparable patients. However, DeKay et al. [11] found that the information in the scenario used by Redelmeier and Tversky differed between bedside and policy level. Using a revised version of the scenario, they performed a new test that resulted in a higher proportion of recommendations to the patient group compared to the individual patients, i.e., the opposite result to Redelmeier and Tversky. Thus, existing empirical evidence is inconclusive.

Many psychological theories argue that emotions and affect are important components of decision making [12-14], and, moreover, that different mental processes may be involved when judging a specific target (an individual) compared to judging a general target (a group) [15]. Both of these aspects are highly relevant to decision making in health care. Rationing at the bedside level is arguably more difficult and emotionally burdensome than rationing at the policy level, primarily because the physician meets the patient face-to-face. The negative consequences of denying care to the patient becomes very real and tangible to the physician making decisions at the bedside. On the contrary, rationing at the policy level concerns denying care to a group of patients, meaning that the negative consequences pertain to a statistical and anonymous patient rather than a single, identified patient. This relates to what is known as the identifiable victim effect in psychology, i.e., that individual decision makers are more willing to help individuals that are presented as identified rather than anonymous victims. The identifiable victim effect have been extensively explored in general helping dilemmas where people are asked to donate to charity [14, 16-21], but to date not thoroughly explored in the context of medical decision making (however see [22]). Given that rationing decisions often entail a trade-off between efficiency and equality, the issue of rationing at the policy vs. bedside level is also related to how policy descriptions affect the efficiency vs. equality tradeoff. Studies have found that when policies describe specific outcomes people become more oriented towards efficiency concerns, while they gravitate towards equality concerns when policies on resource allocation are described in more general terms [23, 24]. 
Such findings suggest that level of abstraction used to describe hard choices prompts emphasis on different values.

In this study we explore (i) whether and to what extent rationing decisions at the bedside differs from rationing decisions taken at the policy level, and (ii) whether such a difference is more pronounced for life-saving decisions as opposed to decisions concerning quality-of-life improvements. To this end, we conduct a large-scale behavioral experiment where both medical and non-medical students make a series of rationing decisions either at the bedside level or at the policy level. We hypothesized that rationing decisions would be less prevalent in the bedside condition (Hypothesis 1) and for life-saving scenarios (Hypothesis 2), due to the emotional nature of the decision.

\section{Methods}

\section{Participants \& Materials}

We conducted a randomized experiment at Linköping University during March 2015, involving both medical students and students from other undergraduate programs. Subjects were recruited on campus and completed a pen-and-paper questionnaire containing a series of rationing scenarios. We implemented a $2 \times 2$ experimental design, with subjects randomly assigned to either a bedside or a policy condition (between-subject variation) that contained twelve rationing scenarios. Each scenario involved one decision, concerning either a lifesaving medical treatment or a quality-of-life improving medical treatment (within-subject variation). All scenarios were identical across the bedside and policy condition except for the level of decision making: In the policy condition, subjects took the role of head of department and made decisions regarding a patient based upon group statistics. At bedside level, subjects instead took the role of a physician and made decisions regarding a single patient who was presented with name and picture. Scenarios were presented in two fixed orders to control for potential order effects. At the end of the experiment, subjects were asked about age, gender, and how emotionally burdensome they experienced the scenarios.

Each rationing scenario was described in three paragraphs and at the end the respondent made his or her decision whether to offer a particular treatment, which was given at the hospital level in the policy condition and to a single, identified, patient in the bedside condition. The first paragraph introduced the situation, and respondents were reminded of their role: "You are a physician," or "You are the head of a department." The second paragraph described briefly the disease treatment based on medical and economical aspects, and this information was identical between the decision-making contexts. The last paragraph was also identical across decision-making contexts and provided information about the alternative use of money by stating that the cost associated with the treatment would otherwise be used to fund other treatments in the hospital describes the. All scenarios can be found in Supplementary Materials available upon request.

Five of the rationing scenarios involved life-saving treatments and six involved quality of life improving treatments. The five life-saving treatments covered different disease areas, e.g. various forms of cancer, prenatal births, and heart disease. The six quality of life improving treatments covered treatments for Alzheimer, diabetes, hearing impairment, hyperhidrosis, 
growth disorder and chronic obstructive pulmonary disease (COPD). In order to make comparisons with previous studies that explored differences in medical decision making for individuals and groups, we also included a twelfth scenario. This scenario was a direct replication of the scenario used in De Kay et al. [11], which is the revised version of the scenario developed by Redelmeier and Tversky [10].

\section{Analysis}

Responses were coded 1 for recommend medication and 0 for recommend against medication for the blood disease scenario. All other scenarios were coded 0 for provide treatment ("Yes") and 1 for do not provide treatment ("No"). Our main dependent variable is the proportion of rationing decisions calculated at the level of the individual, i.e. the rate at which individuals choose do not provide treatment. We use two-sided t-tests to investigate our main hypotheses, except for the blood condition where we use a $\chi^{2}$ test. The interaction between type of scenario (life-saving vs. quality of life) and level of decision making (bedside vs. policy) is analyzed using a mixed-design ANOVA. The effects of age and gender are investigated using regression analysis, and we test for order effects by comparing the proportion of rationing decisions (all scenarios) across the two orders for the bedside condition, the policy condition, and, finally, for both conditions jointly. Subjects also indicated (at the end of the experiment) how emotionally burdensome they experienced the scenarios. These answers were recorded on a six-point Likert scale, ranging from 1 ("not at all”) to 6 ("highly burdensome"). 


\section{Results}

In total, 573 subjects participated in the experiment. Mean age among respondents was 23.6 years and 52.4\% were women. Medical students represented $54.3 \%$ of subjects in the sample. About half of the medical students in the sample (47.7\%) had studied more than six semesters, meaning they have some experience from clinical practice. Among the nonmedical students in the sample, most studied either Engineering (39.7\%) or Business and Administration (29.8\%). As shown in Table 1, there were no differences in the background characteristics (age, sex and educational background) between experimental conditions (bedside level vs. policy level).

Table 1. Background characteristics, by decision level (Bedside level vs Policy level)

\begin{tabular}{lrr}
\hline & Bedside-level & Policy-level \\
\hline $\mathrm{N}$ & 289 & 284 \\
Female, n (\%) & $152(52.6 \%)$ & $148(52.1 \%)$ \\
Age, mean (SD) & $23.7(3.66)$ & $23.5(3.24)$ \\
Medical Students, n (\%) & $157(54.3 \%)$ & $154(54.2 \%)$ \\
\hline
\end{tabular}

Note: Subjects were randomly assigned to either the Bedside or Policy condition.

We begin by reporting the results for the incurable blood condition, previously used by Redelmeier \& Tversky [10] and Dekay et al. [11]. A higher proportion of subjects recommended care at the policy level compared to bedside level in our replication, but the difference is not statistically significant ( $54 \%$ vs. $49 \%, \chi^{2}(1)=1.486, \mathrm{p}=0.223, \mathrm{~h}=0.102$ ). This result is different from Redelmeir and Tversky but in line with DeKay et al.

Figure 1 shows our main results. We found no overall difference in the mean rate of rationing between bedside and policy level (Mean Rate: 0.438 vs. $0.459, \mathrm{t}(571)=-1.60, \mathrm{p}=0.110$, $\mathrm{d}=-0.134)$. A mixed-design ANOVA revealed a significant interaction effect between level of decision making and type of scenario $\left(F(1,571)=9.894, p=0.002, \eta_{p}{ }^{2}=0.017\right)$. The main effect of decision level was significant and amounted to 6.3 percentage points for life-saving treatments $\left(\mathrm{F}(1,571)=11.751, \mathrm{p}=0.001, \eta_{\mathrm{p}}{ }^{2}=0.020\right)$, but it was smaller and insignificant for quality-of-life improving treatments $\left(F(1,571)=0.441, p=0.507, \eta_{p}{ }^{2}=0.001\right)$. This partly confirms Hypothesis 1 . We can also see in the figure that quality of life-improvements are rationed more frequently than life-saving treatments, both at the bedside and policy level, which is clearly in line with Hypothesis 2. Taken together, subjects were much more reluctant to deny life-saving treatments at the bedside level compared to at the policy level. A potential reason for this effect could be the emotional nature of the decision. To explore this possibility, we had included a follow-up question at the end of the experiment, asking subjects to indicate (on a six-point Likert scale) how emotionally burdensome they experienced the scenarios. Subjects in the bedside condition appeared to experience the scenarios as more emotionally burdensome, and this effect was marginally significant (3.495 vs 3.265, $\mathrm{t}(550)=1.814, \mathrm{p}=0.070, \mathrm{~d}=0.154)$. 
Figure 1. Health care rationing decisions at the bedside and policy level.

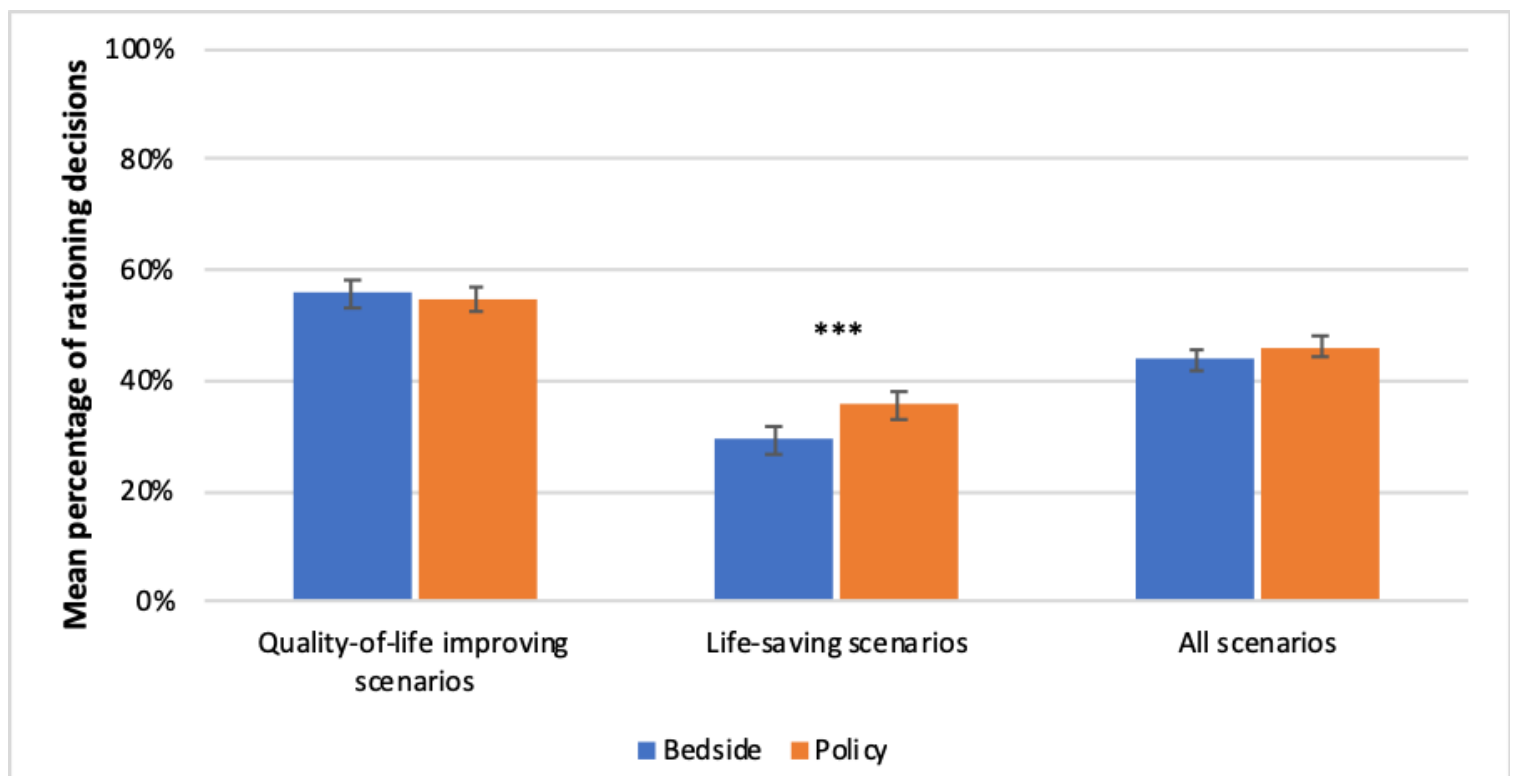

Note: The figure shows the proportion of decisions that were in favor of rationing (denying) medical care. Error bars represent $95 \%$ Confidence Intervals.

$* \mathrm{p}<0.05, * * \mathrm{p}<0.01, * * * \mathrm{p}<0.001$

Table 2 presents descriptive results for medical students vs. non-medical students. The main effect of decision level was significant when the sample was restricted to medical students (Mean Rate: 0.448 vs. $0.443, \mathrm{t}(309)=-2.190, \mathrm{p}=0.029, \mathrm{~d}=-0.248)$. Medical students were also more likely to ration care overall, compared to non-medical students (Mean Rate: 0.466 vs. 0.428, $t(571)=-2.838, p=0.005$. $d=-0.238)$. The effect appeared to be greater for scenarios involving life-saving treatments, where the difference in the mean rate of rationing decisions between medical and non-medical students was 5.0 percentage points, but the interaction between type of scenario and study program (medical vs. non-medical) was not significant in a mixed-design ANOVA $\left(\mathrm{F}(1,571)=0.95, \mathrm{p}=0.33, \eta_{\mathrm{p}}{ }^{2}=0.002\right)$. The descriptive results also indicated a stronger difference between medical and non-medical students at the policy level (5.3 percentage points) compared to bedside level (2.4 percentage points), but the interaction between decision level and study program was not significant in a two-way between subjects design ANOVA $\left(F(1,569)=1.195, p=0.275, \eta p^{2}=0.002\right)$.

Table 2. Rationing decisions, by medical students and other students

\begin{tabular}{lcccc}
\hline & $\begin{array}{c}\text { Medical } \\
\text { students } \\
\mathrm{n}=311\end{array}$ & $\begin{array}{c}\text { Non-medical } \\
\text { students } \\
\mathrm{n}=262\end{array}$ & diff & p-value \\
\hline Total (Bedside and policy): & & & & \\
$\quad$ All scenarios & 0.466 & 0.428 & 0.038 & 0.005 \\
Life-saving scenarios & 0.347 & 0.296 & 0.050 & 0.007 \\
Quality of life-improving scenarios & 0.564 & 0.537 & 0.027 & 0.126 \\
Bedside: & & & & \\
All scenarios & 0.448 & 0.425 & 0.024 & 0.214 \\
Life-saving scenarios & 0.305 & 0.278 & 0.027 & 0.272 \\
Quality of life-improving scenarios & 0.566 & 0.547 & 0.019 & 0.435
\end{tabular}


Policy:

\begin{tabular}{lllll} 
All scenarios & 0.483 & 0.430 & 0.053 & 0.006 \\
Life-saving scenarios & 0.389 & 0.315 & 0.074 & 0.008 \\
Quality of life-improving scenarios & 0.562 & 0.527 & 0.035 & 0.163 \\
\hline
\end{tabular}

Note: The table shows the proportion of decisions that were in favor of rationing (denying) medical care.

To further explore the descriptive results, we conducted regression analyses on rationing decisions controlling for age and gender. Results are presented in Table 3. In line with what we could see in Figure 2, there is no difference between policy and bedside level when looking at all scenarios. There is however a significant effect when looking at life-saving scenarios only, where subject in the bedside condition are 5.9 percentage points less likely to deny care to their patients $(\beta=-0.059, \mathrm{p}=0.002)$. There is no such difference for quality of life improving treatments. We can also see that medical students were more likely to ration care, especially for life-saving scenarios where the estimated difference between medical and nonmedical students is 6.2 percentage points ( $\beta=0.062, \mathrm{p}=0.002)$. Interestingly, women were significantly more reluctant to ration care, primarily in life-saving scenarios where the difference to men amounted to 3.9 percentage points $(\beta=-0.039, p=0.040)$. Subjects who rationed quality of life improving treatments were also more likely to ration life-saving treatments $(\beta=0.120, p=0.007)$. We also tested for order effects but found no differences in rationing decisions between the two orders at conventional 5\%-level of significance. 
Table 3. OLS regression on rationing decisions

\begin{tabular}{|c|c|c|c|c|}
\hline & $\begin{array}{l}\text { Quality-of- } \\
\text { life } \\
\text { Improving } \\
\text { scenarios } \\
\text { Coef. (se) }\end{array}$ & $\begin{array}{l}\text { Life-saving } \\
\text { scenarios }\end{array}$ & All scenarios & $\begin{array}{l}\text { Life-saving } \\
\text { scenarios }\end{array}$ \\
\hline Constant & $\begin{array}{l}0.589 * * * \\
(0.062)\end{array}$ & $\begin{array}{l}0.376^{* * *} \\
(0.065)\end{array}$ & $\begin{array}{l}0.491 * * * \\
(0.047)\end{array}$ & $\begin{array}{l}0.305^{* * *} \\
(0.070)\end{array}$ \\
\hline Bedside & $\begin{array}{c}0.006 \\
(0.018)\end{array}$ & $\begin{array}{l}-0.059 * * \\
(0.018)\end{array}$ & $\begin{array}{l}-0.022 \\
(0.013)\end{array}$ & $\begin{array}{l}-0.059 * * \\
(0.018)\end{array}$ \\
\hline Medical & $\begin{array}{c}0.033 \\
(0.018)\end{array}$ & $\begin{array}{l}0.062 * * \\
(0.019)\end{array}$ & $\begin{array}{l}0.046^{* *} \\
(0.014)\end{array}$ & $\begin{array}{l}0.058 * * \\
(0.019)\end{array}$ \\
\hline Female & $\begin{array}{l}-0.022 \\
(0.018)\end{array}$ & $\begin{array}{l}-0.039 * \\
(0.019)\end{array}$ & $\begin{array}{l}-0.030^{*} \\
(0.014)\end{array}$ & $\begin{array}{l}-0.037 \\
(0.019)\end{array}$ \\
\hline Age & $\begin{array}{l}-0.002 \\
(0.003)\end{array}$ & $\begin{array}{l}-0.002 \\
(0.003)\end{array}$ & $\begin{array}{l}-0.002 \\
(0.002)\end{array}$ & $\begin{array}{l}-0.001 \\
(0.003)\end{array}$ \\
\hline $\begin{array}{l}\text { Quality-of-life } \\
\text { Improving scenarios }\end{array}$ & & & & $\begin{array}{l}0.120^{* *} \\
(0.044)\end{array}$ \\
\hline $\mathrm{n}$ & 556 & 556 & 556 & 556 \\
\hline
\end{tabular}

Note: The dependent variable is the rate at which individuals deny care (each decision in a scenario is coded 0 for provide treatment and 1 for do not provide treatment). Bedside is a dummy for level of decision making, Medical is a dummy for medical student, and Female is a gender dummy. ${ }^{*} \mathrm{p}<0.05,{ }^{* *} \mathrm{p}<0.01,{ }^{* * *} \mathrm{p}<0.001$

\section{Discussion}

It is important to understand the behavioral differences in rationing decisions taken at different levels in the health care system. A bias in decision making at one level or the other has implications for patient outcomes, and thus for the design of fair and efficient prioritysetting policies in health care. We found a discrepancy between health care rationing at policy and bedside level for scenarios involving life-saving decisions, where subjects rationed treatments to a greater extent at the policy level compared to bedside level. Medical students were more likely to ration care compared to non-medical students. Follow-up questions indicated that bedside rationing was somewhat more emotionally burdensome, which is in line with psychological mechanisms believed to influence behavior in helping dilemmas. In contrast to Redelmeier and Tversky [10] we did not find a difference between decisions at policy and bedside level for the blood disease scenario, a finding which is in line with the follow-up study by DeKay et al. [11].

The fact that we couldn't replicate Redelmeier and Tversky and moreover that we found no difference in rationing decisions between bedside and policy level for quality of lifeimproving treatments suggest that behavioral differences are smaller than previously thought. Nevertheless, we did find an effect for life-saving treatments, where there was a robust 6.3 percentage-point gap in rationing decisions between bedside and policy level. This result is in line with the hypotheses that bedside rationing is more demanding due to the emotional nature of the decision. 
Taken together, our results indicate a robust "bedside effect" in the life-saving domain of health care rationing decisions. Interestingly, this effect was significant also when the sample was restricted to medical students. We did not have a clear hypothesis for the comparison between medical and non-medical students. On the one hand, we could have expected medical students to be less influenced by the experimental manipulation, due to their greater experience in medical judgment. On the other hand, however, medical students' current clinical experience (from their training) has most likely concerned bedside decision making, meaning that the bedside condition in the experiment should possibly exert a stronger influence on them compared to other students. This would be in line with the finding that medical students primed to think about the importance of the Hippocratic Oath (which embodies a duty to think first-handed about their own patients) were more altruistic toward patients but also showed less concern for efficiency and third-party payers' provision costs [25]. The main takeaway, however, is the fact that the "bedside effect" prevailed in the sample of medical students (future clinicians), which again suggests that the effect is robust and likely to influence real life medical decision making.

Our study extends previous research on priority setting, using a randomized experiment on rationing decisions in hypothetical scenarios. This type of design typically has high internal validity, and the large sample size ensures that our statistical tests are high-powered based on effect sizes observed in previous studies. The most obvious limitation with our research paradigm is the hypothetical nature of decisions. In real life the emotional discrepancy between decision making at the bedside and the policy level is arguably more salient. Although this limitation should be acknowledged, it most likely contributes to an underestimation of the true bedside effect. Especially given the gentle nature of our experimental manipulation where we in the policy versions position respondents as “departmental head”. Moreover, survey research can often be biased-to-the-null from thoughtless and careless responses, which may further contribute to an underestimation of the true bedside effect.

To conclude, this study contributes to the policy debate about fair and efficient rationing, by establishing empirical facts about the discrepancy between rationing decisions taken at the bedside and policy level. More specifically it suggests that allocation preferences may be conflicting partly because they are formed at different levels of the health care system (bedside vs. policy). Although it is probably not realistic (or even preferable) to think that that preferences over hard choices should always be similar across bedside and policy level, it is important to be attentive to discrepancies that are systematic, and to be aware of the role emotions might play in medical decision making. Some countries like Sweden and Norway have taken measures to counter variation in priority-setting decisions by introducing guiding principles. Still, in the end all health care rationing decisions must be implemented patient by patient, and there are always large elements of judgment in decisions about treatment for each new patient.

\section{Declaration of conflicting interests}

The authors declare that there is no conflict of interests. 


\section{References}

1. Tinghög, G., The art of saying no : the economics and ethics of healthcare rationing (thesis). 2011, Linköping: Linköping University Press.

2. Ubel, P.A. and S. Goold, Recognizing bedside rationing: clear cases and tough calls. Annals of Internal Medicine, 1997. 126(1): p. 74-80.

3. Le Grand, J., Motivation, agency, and public policy: Of knights and knaves, pawns and queens. 2003, Oxford: Oxford University Press.

4. Levinsky, N.G., Truth or consequences. N Engl J Med, 1998. 338(13): p. 913-5.

5. Smith, R., H. Hiatt, and D. Berwick, Shared ethical principles for everybody in health care: a working draft from the Tavistock group. Bmj, 1999. 318(7178): p. 248-51.

6. Weinstein, M.C., Should physicians be gatekeepers of medical resources? J Med Ethics, 2001. 27(4): p. 268-74.

7. Morreim, E.H., Fiscal scarcity and the inevitability of bedside budget balancing. Arch Intern Med, 1989. 149(5): p. 1012-5.

8. Ubel, P.A., Physicians, thou shalt ration: the necessary role of bedside rationing in controlling healthcare costs. Healthc Pap, 2001. 2(2): p. 10-21.

9. Ubel, P.A. and R.M. Arnold, The unbearable rightness of bedside rationing. Physician duties in a climate of cost containment. Arch Intern Med, 1995. 155(17): p. 1837-42.

10. Redelmeier, D.A. and A. Tversky, Discrepancy between medical decisions for individual patients and for groups. N Engl J Med, 1990. 322(16): p. 1162-4.

11. DeKay, M.L., et al., Further explorations of medical decisions for individuals and for groups. Med Decis Making, 2000. 20(1): p. 39-44.

12. Kahneman, D., Maps of bounded rationality: Psychology for behavioral economics. American Economic Review, 2003. 93(5): p. 1449-1475.

13. Sloman, S.A., The empirical case for two systems of reasoning. Psychological Bulletin, 1996. 119(1): p. 3-22.

14. Small, D.A. and G. Loewenstein, Helping a victim or helping the victim: Altruism and identifiability. Journal of Risk and Uncertainty, 2003. 26(1): p. 5-16.

15. Hamilton, D.L. and S.J. Sherman, Perceiving persons and groups. Psychol Rev, 1996. 103(2): p. 336-55.

16. Västfjäll, D., et al., Compassion fade: Affect and charity are greatest for a single child in need. PLoS One, 2014. 9(6).

17. Kogut, T. and I. Ritov, The "Identified victim" effect: An identified group, or just a single individual? Journal of Behavioral Decision Making, 2005. 18(3): p. 157-167.

18. Kogut, T. and I. Ritov, The singularity effect of identified victims in separate and joint evaluations. Organizational Behavior and Human Decision Processes, 2005. 97(2): p. 106116.

19. Kogut, T. and I. Ritov, The identifiable victim effect: Causes and boundary conditions, in The Science of Giving: Experimental Approaches to the Study of Charity, D.M. Oppenheimer and C. Olivola, Editors. 2011, Psychology Press: New York. p. 133-145.

20. Jenni, K. and G. Loewenstein, Explaining the Identifiable Victim Effect. Journal of Risk and Uncertainty, 1997. 14(3): p. 235-257.

21. Wiss, J., et al., The influence of identifiability and singularity in moral decision making. Judgment and decision making, 2015. 10(5): p. 492-502.

22. Wiss, J., et al., Prioritizing Rare Diseases: Psychological Effects Influencing Medical Decision Making. Medical Decision Making, 2017. 37(5): p. 567-576.

23. Colby, H., J. DeWitt, and G.B. Chapman, Grouping Promotes Equality: The Effect of Recipient Grouping on Allocation of Limited Medical Resources. Psychological Science, 2015. 26(7): p. 1084-1089. 
24. Li, M. and J. DeWitt, Equality by principle, efficiency by practice: How policy description affects allocation preference, in Interdisciplinary Perspectives on Fairness, Equity, and Justice. 2017. p. 67-91.

25. Kesternich, I., H. Schumacher, and J. Winter, Professional norms and physician behavior: Homo oeconomicus or homo hippocraticus? Journal of Public Economics, 2015.

131(Supplement C): p. 1-11. 